\title{
CUR-CA-THIONE: A NOVEL CURCUMIN CONCOCTION WITH ENHANCED WATER SOLUBILITY AND BRAIN BIO-AVAILABILITY
}

\author{
DEVANG Y. SHELAT ${ }^{1}$, SANJEEV R. ACHARYA ${ }^{2}$ \\ Institute of Pharmacy, Nirma University, Sarkhej Gandhinagar Highway, Ahmedabad 382481 \\ Email: shelat.devang@gmail.com
}

Received: 07 Sep 2016 Revised and Accepted: 21 Oct 2016

\section{ABSTRACT}

Objective: Curcumin, is widely studied as a potential drug in treating various disorders but lacks applicability due to poor water solubility and tissue bioavailability. The main objective of the study was to develop a formulation of curcumin that has enhanced water solubility and brain bioavailability.

Methods: A curcumin concoction was prepared using solvent evaporation technique taking casein and glutathione as vectors. Various process parameters were identified namely time, temperature, $\mathrm{pH}$ and vector while formulation parameters included drug entrapment, anti-oxidant activity, and water solubility. The concoctions were evaluated for in vitro release kinetics at three pH i.e. $1.2,4.5$ and 6.2 at six-time intervals i.e. $10,20,30$ 40, 60, 120 min using dialysis bag membrane. The same kinetics was further validated using same time points with wistar rats and giving concoction at a single dose of $2 \mathrm{~g} / \mathrm{kg}$ via the oral route.

Results: A concoction i.e. CUR-CA-THIONE having significant entrapment efficiency (77.83\%, 97.75\%, 90.19\%), water solubility (40, 350 and 45 times than normal curcumin) and DPPH activity (IC $50: 28.91,25.07$ and 27.89) was evaluated in concoctions CUR-CA-THIONE-T.1, CUR-CA-THIONET.2 and CUR-CA-THIONE-T.3 respectively. These formulations were then carried out for in vitro release profile at different pH with average release obtained between 20-30 min. In vivo kinetics was studied by isolating tissues like brain, liver, lung, kidney and spleen in male wistar rats and maximum brain bioavailability was observed for CUR-CA-THIONE-T.3 at $30 \mathrm{~min}$ with $75 \mathrm{ng} / \mathrm{g}$ of brain tissue.

Conclusion: The experiment helps in concluding that CUR-CA-THIONE has improved its water solubility and is able to by-pass systemic circulation to targeted activity.

Keywords: Curcumin, Brain, CUR-CA-THIONE, Solubility, Tissue

(C) 2016 The Authors. Published by Innovare Academic Sciences Pvt Ltd. This is an open access article under the CC BY license (http://creativecommons.org/licenses/by/4. 0/A

DOI: http://dx.doi.org/10.22159/ijpps.2016v8i12.15093

\section{INTRODUCTION}

Curcumin (diferuloylmethane), a yellow pigment found in Curcuma longa (turmeric) have different pharmacological actions like antioxidant, anti-inflammatory, anticancer, antiviral and many more [1-3]. Moreover, curcumin is prescribed in Indian medicine for treatment for respiratory conditions (asthma, bronchial hyperactivity, and allergy), anorexia, cough, hepatic diseases and sinusitis $[4,5]$. Curcumin in a clinical trial has shown to be non-toxic at $8 \mathrm{~g} / \mathrm{kg}$ oral dose [6, 7]. Moreover, a detectable amount of curcumin is perceived at $400 \mathrm{mg} / \mathrm{kg}$ in the in vivo study [8].

Curcumin has said to be metabolized in intestine and liver with denaturation to form glucuronide and sulfate conjugate thus exhibiting its restricted oral bioavailability $[9,10]$. It is proved that curcumin acts as a potential agent in chronic neurodegenerative ailments [11-13]. However, curcumin has not been approved as a single drug of choice regardless of its significant pharmacological potential. It has been studied till Phase-II clinical study, but its bioavailability is still an issue (Biological Classification System-IV \{BCS-Class-IV\}). Furthermore, poor aqueous solubility, relatively low bioavailability, and intense staining color of curcumin have been major problems [14,15].

Nonetheless, curcumin bioavailability could be enhanced with the use of different vectors, surface modifiers, size reduction and many other ways [16, 17]. Glutathione is present in the brain for cell signaling thus glutathione is taken as the main vector to imbibe through the blood-brain barrier (BBB) [18]. Glutathione also acts as a self-oxidizing agent thus lead to be a potential antioxidant agent. Casein a phosphoprotein having a tertiary structure majorly found in milk and related products. The selection of casein was done due to its complex chain of carbon atoms and curcumin binding [19]. In current hypothesis, a surface modified curcumin was prepared using glutathione and casein as vectors to increase its water solubility and bioavailability. There are various formulations of curcumin that are currently available in the market with liposome or nanoparticle preparations [20] and one of the formulation is selected as market standard. The rationale of the study was to develop a formulation having enhanced water solubility and bioavailability.

\section{MATERIALS AND METHODS}

\section{Chemicals and reagents}

Casein (CDH, India), curcumin (90\%) (K. Patel Phyto Extracts, Vapi, Gujarat, India), and glutathione (Sigma-Aldrich, U. S.). All solvents and chemicals were analytical or HPLC grade.

\section{Formulation development}

The curcumin-based formulation was prepared with use of glutathione and casein as vectors through solvent evaporation technique, through previously described method [21]. Briefly, the vector is dissolved in a suitable water immiscible solvent, and the drug is dispersed or dissolved in this polymeric solution. The resultant solution or dispersion is then emulsified in continuous aqueous phase to form discrete droplets. Further, organic solvent must diffuse into an aqueous phase and then evaporated in the water-to-air interface. As solvent evaporation initiates, the free flowing mixture can be obtained after suitable filtration and drying. In the present study, we have selected glutathione and casein as vectors to enhance water solubility and brain bioavailability. Three complexes were prepared depending on the drug-to-vector ratio of 9:1, 8:2 and 7:3 for curcumin-glutathione (CUGU), curcumin-casein (CUCAS) and curcumin-casein-glutathione (CUCASGU) complex. Briefly, curcumin $(9 \mathrm{~g})$ was solubilized in $25 \mathrm{ml}$ of methanol, while glutathione/casein $(1 \mathrm{~g})$ was dissolved in $10 \mathrm{ml}$ of distilled water. Curcumin was added dropwise in glutathione phase with continuous magnetic stirring (800 rpm, Remi Magnetic Stirrer) (30 min) along 
with heating $\left(40^{\circ} \mathrm{C}\right)$. Further, after $30 \mathrm{~min}$ had obtained mixture was vacuum dried and dry powder of CUGU, CUCAS, and CUCASGU complex was acquired. Similar batches were prepared at a different ratio of $8: 2$ and 7:3 respectively. Three parameters namely entrapment efficiency, drug loading, and solubility were stratified for selection of best ratio as CUR-CA-THIONE.

\section{Entrapment efficiency}

Entrapment efficiency is an important parameter for characterizing solid lipid particles. The entrapment efficiency of dispersion was determined by centrifugation method. In order to attain optimal encapsulation efficiency, several factors were varied including the volume of solvent, the amount of vector, type of vector, processing time, system temperature, stirring time, stirring speed (rpm) and $\mathrm{pH}$ of the system [22]. The dispersion was centrifuged at $10000 \mathrm{rpm}$ for $10 \mathrm{~min}$ in a refrigerated centrifuge to collect supernatant liquid. The collected liquid was filtered to measure free drug concentration after suitable dilution with a fresh phosphate buffer saline (pH 7.4) The absorbance was measured at $425 \mathrm{~nm}$ in an ultraviolet spectrophotometer (UV). Efficiency of entrapment was determined in reference to loading ratio and total dried dispersion weight obtained [23] using following equation:

$$
\% E E=\left\lfloor\frac{(W \text { formulation } X D L)}{W \text { loaded }}\right\rfloor X 100
$$

Where $\%$ EE is the efficiency of entrapment (percent) and stands for the total mass of powders obtained after freeze-drying; $\mathrm{W}$-Formulation = weight of mark obtained; $W_{\text {-Loaded }}=$ weight of drug-loaded; $\mathrm{DL}=\mathrm{drug}$ loading ratio.

\section{Solubility study}

The solubility of a drug determines its route of absorption and its probable uptake mechanism. The solubility is determined by taking $100 \mathrm{mg}$ drug in a vial and adding dropwise water till completely solubilized with occasional vortex [24].

\section{Physical properties}

The compatibility and interaction between drug and vector were identified by a change in fourier transform infrared (FTIR; Shimadzu) spectroscopy. The pellets were prepared with potassium bromide $(\mathrm{KBr})$ using the pure drug, polymers and crushed tablet formulations and analyzed in the frequency range between wave numbers 4000 to $400 \mathrm{~cm}^{-1}$ at $4 \mathrm{~cm}^{-1}$ resolution.

The differential scanning calorimetry (DSC) analysis of drug and formulations were carried out (Shimadzu DSC 60, Japan) to evaluate any possible drug-polymer interaction [25]. Briefly, 5-6 mg samples were hermetically sealed in an aluminum crucible and heated at a constant rate of $10{ }^{\circ} \mathrm{C} / \mathrm{min}$ over a temperature range of $40^{\circ}$ to 300 ${ }^{\circ} \mathrm{C}$. The inert atmosphere was maintained by purging nitrogen gas at a flow rate of $50 \mathrm{ml} / \mathrm{min}$ [26].

\section{Anti-oxidant analysis}

Briefly, 2, 2, diphenyl-1-picrylhydrazyl (DPPH) is diluted in methanol to give a purple color and stored in an amber color bottle. To $100 \mu \mathrm{l}$ of the diverse concentration of sample, $4 \mathrm{ml}$ of $0.004 \%$ methanolic solution of DPPH was added. After 30 min incubation absorbance was read at $517 \mathrm{~nm}[27,28]$. Inhibition of free radical by DPPH in \% was calculated by the following equation:

$$
\%=\frac{A \text { blank }- \text { A sample }}{\text { A blank }} X 100
$$

A blank: absorbance of control reaction, A sample: absorbance of the test sample.

\section{In vitro release profile}

The in vitro release profile of formulation was observed taking $1 \mathrm{~g}$ of the drug in a dialysis membrane (Himedia, Avg. Dia.: $21.5 \mathrm{~mm}$ ) $[29,30]$. The drug is loaded films were suspended in glass vessels containing $50 \mathrm{ml}$ of $0.1 \mathrm{M}$ phosphate buffer saline (PBS; pH: 1.2., 4.5 and 7.4). At appropriate time intervals $(10,20,30,40,60,120 \mathrm{~min})$ aliquots of solutions were withdrawn and the amount of curcumin released were evaluated by UV spectrophotometer at $424 \mathrm{~nm}$ [31]. The release was quantified by the following equation:

$$
\% \text { Release }=\frac{\text { Release curcumin }}{\text { Total curcumin }} \times 100
$$

\section{LC-MS/MS analysis}

The method specificity was investigated by comparing chromatogram of blank plasma with standard solutions and samples collected from rats post curcumin administration. The linearity of the bioanalytical assay was evaluated with a total of eight calibration standards over the concentration range of $0.5-500 \mathrm{ng} / \mathrm{ml}$. Calibration curves were constructed by linear least squares regression analysis plotting peak area ratios versus drug concentrations [32]. The mobile phase consisted of acetonitrile, methanol, and acetic acid in mixture $\mathrm{A}$ and water ammonium formate in mixture B. The extraction of curcumin from plasma was carried out with $4 \%$ hydrochloric acid in water. Carbamazepine was taken as internal standard and stock solution of $1 \mathrm{mg} / \mathrm{ml}$ was prepared. Instrument condition was electron spray ionization, positive polarity of ACE C- 18 column ( $100 \mathrm{~mm} \mathrm{X} 4.6 \mathrm{~mm}, 5 \mathrm{um})$. The column temperature was kept at $40^{\circ} \mathrm{C}$, and $10 \mu$ injections.

\section{Preparation of curcumin standards}

A concentrated stock standard of curcumin, glutathione and casein were prepared by dissolving $10 \mathrm{mg}$ of each compound in $10 \mathrm{ml}$ of methanol, generated a stock solution of $1 \mathrm{mg} / \mathrm{ml}$. An eight point calibration curves were prepared by serial dilution of curcumin stock solution in the range of $0.5-500 \mathrm{ng} / \mathrm{ml}$.

\section{Animals}

Protocol for animals was carried out through approval of Institutional animal ethics committee (Protocol No.: IP/PCOG/ CONS/16/031) and Committee for the purpose of control and supervision of experiments on animals (CPCSEA). Male spraguedrawly (SD) rats (300-350 g) were (Zydus research center: ZRC, Ahmedabad) and maintained at the animal house (Institute of Pharmacy, Nirma University, Ahmedabad) under ideal conditions (Temp.: 20-25 ${ }^{\circ} \mathrm{C}$; humidity: $50 \pm 5 \%$ ). They were provided with water and food ad libitum until further use.

\section{Pharmacokinetic study}

In the present investigation, a different formulation was taken, curcumin (Reference Standard), curcumin-casein complex, curcumin-glutathione complex, curcumin-casein-carnosine complex and marketed formulation. Male wistar rats (250-300 g) were selected for the study. Estimation of bioavailability of curcumin was estimated in blood, brain, liver, lung, kidney and spleen. Group-1 consisted of curcumin- $90 \%$ at a dose of $2 \mathrm{~g} / \mathrm{kg}$ body weight while group-2 consisted of the curcumin-glutathione complex at a dose of $2 \mathrm{~g} / \mathrm{kg}$ body weight. Group-3 consisted of the curcumin-casein complex at a dose of $2 \mathrm{~g} / \mathrm{kg}$ body weight, while group- 4 consisted of the curcumin-casein-glutathione complex at a dose of $2 \mathrm{~g} / \mathrm{kg}$ body weight. Moreover, group-5 consisted of standard curcumin marketed formulation at a dose of $2 \mathrm{~g} / \mathrm{kg}$ body weight. All dose were considered equivalent to $\mathrm{CU}-90 \%$ at $500 \mathrm{mg}$ dose calculated using high-pressure liquid chromatography (HPLC) analysis. Animals were given a single dose of the drug (oral route-po) and were sacrificed at $0,20,30,40,60$ and $120 \mathrm{~min}$ [33]. Blood was stored in preheparinized vials and tissue was stored at $-20{ }^{\circ} \mathrm{C}$ until further use. Further, the brain was homogenized, and samples were estimated via liquid chromatography-mass spectroscopy (LC-MS/MS) for determination of the amount of curcumin in brain and plasma.

\section{Data analysis and statistics}

In vitro results were expressed as the mean \pm standard deviation (SD) of three replicates while in vivo results were expressed as mean $\pm S D$ of six replicates. Pharmacokinetic parameters were estimated using the model independent method. Statistical analysis of data was performed via one-way analysis of variance (ANOVA). The results were considered statistically significant if $\mathrm{p}<0.05$. 


\section{RESULTS}

\section{Entrapment efficiency}

Curcumin was taken as the reference standard and different formulation namely CUGU, CUCAS and CUCASGU were formulated. Marketed formulation was taken as standard curcumin marketed formulation.

Different formulations were taken at different concentration ratio from which 9:1 was found the optimum in terms of its entrapment efficiency. Thus, for future study ratio of 9:1 will only be used in all formulations. The CUGU complex showed $77.83 \%$ entrapment, CUCAS complex showed entrapment of $97.41 \%$, while CUCASGU showed $90.24 \%$ entrapment (table 1).

Table 1: Entrapment efficiency of different formulations

\begin{tabular}{lll}
\hline Mixture & Ratio & \%EE \\
\hline CU: GU & $9: 1$ & 77.83 \\
CU: CAS & $9: 1$ & 97.75 \\
CU: CAS: GU & $1 \%$ & 90.19 \\
\hline
\end{tabular}

Thus, curcumin shows significant entrapment in all formulations and showed maximum entrapment with casein.

\section{Solubility study}

The solubility of prepared different formulations was observed with absorbance in U. V. spectroscopy. The table 2 shows a significant increase in the fold in water solubility as compared to blank curcumin which was considered as $100 \%$ soluble. Formulation CUGU shows 44 times increase in solubility while CUCAS shows 354 times increase in solubility and formulation CUCASGU shows 42 times increase in solubility. Solubility is carried out on time point analysis until $12 \mathrm{~h}$ to check sedimentation rate in water and data shows no significant change in solubility. The data shows an increase in solubility over time with maximum solubility last between 3-6 h (table 2).

\section{Physical properties}

The properties of the curcumin, glutathione and casein were carried out to justify the conjugation or interaction between them in the formulation. The spectra in FTIR study shows the-OH peak at 2250 $\mathrm{m} / \mathrm{z}$ in all the samples showing no major shifts (fig. 1).

DSC of formulations shows no change in temperature ranging from $175^{\circ}-195^{\circ} \mathrm{C}$ (fig. 2).

Table 2: Solubility Study of different formulations $(n=3)$

\begin{tabular}{llll}
\hline Groups & Increase in fold & \\
\cline { 2 - 4 } & $\mathbf{0 ~ h}$ & $\mathbf{3 ~ h}$ & $\mathbf{6 ~ h}$ \\
\hline CU: GU & $30.09 \pm 2.4$ & $31.82 \pm 3.2$ & $52.30 \pm 5.3$ \\
CU: CAS & $378.21 \pm 26.5$ & $379.84 \pm 28.2$ & $363.40 \pm 23.9$ \\
CU: CAS: GU & $47.85 \pm 3.6$ & $51.42 \pm 4.5$ & $47.89 \pm 3.8$ \\
MF & $32.88 \pm 2.5$ & $34.48 \pm 1.5$ & $30.41 \pm 1.6$ \\
\hline
\end{tabular}

All data are given in mean \pm SD

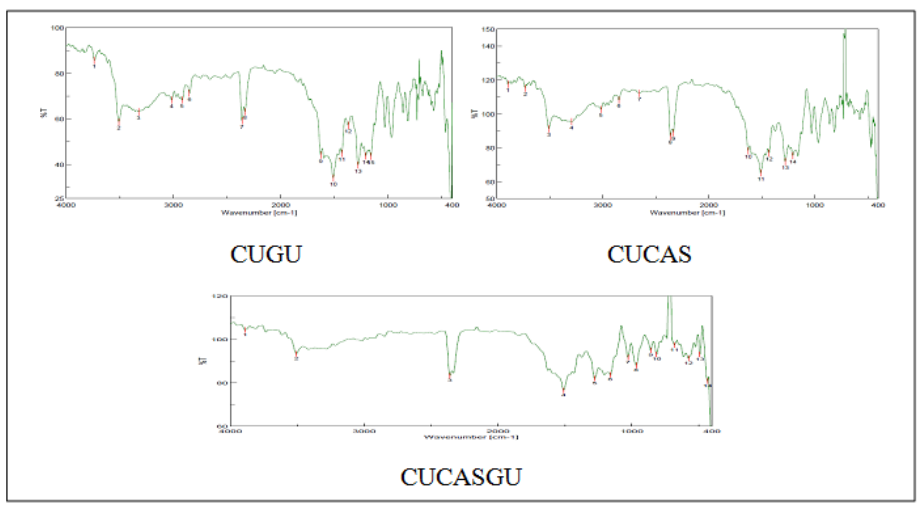

Fig. 1: FTIR spectra of curcumin formulations

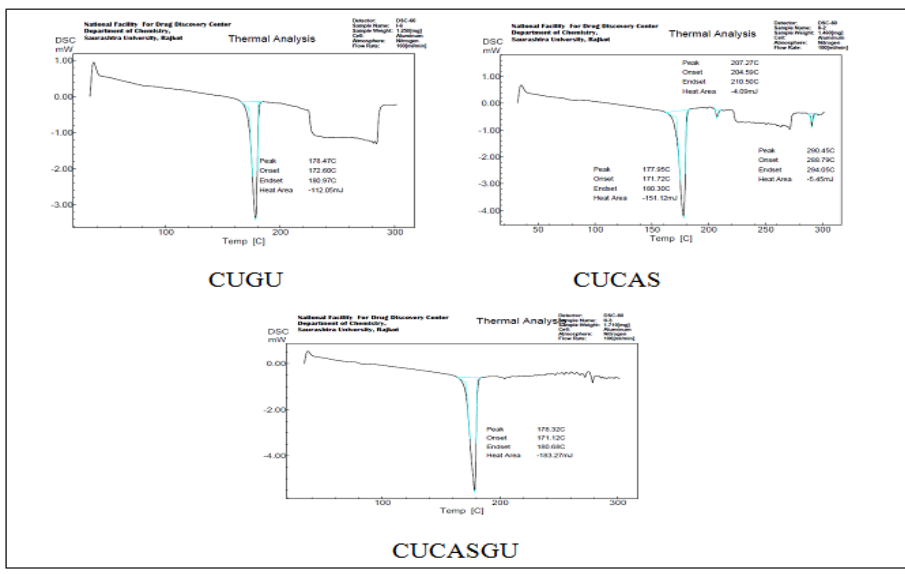

Fig. 2: DSC analysis of curcumin formulations 


\section{Anti-oxidant analysis}

The DPPH activity was carried out for all formulations and inhibition of curcumin standard was found to be maximum at 41.32 while that of the curcumin-casein complex was 28.91, the curcuminglutathione complex was 25.07 and of the curcumin-caseinglutathione complex was 27.89 (table 3 ).

\section{In vitro release profile}

The release kinetics helps in knowing the mechanism of excretion and its removal pathway (fig. 3).

\section{Pharmacokinetic study}

Male wistar rats (avg. wt: 250-300 g) were taken for study at different time points $20,30,40,60$ and 120 min. with 6 animals in each group. Curcumin single dose of $2 \mathrm{~g} / \mathrm{kg}$ body weight was given in all groups (oral; p. o.). Animals were euthanized with a collection of brain, liver, lung, kidney and spleen were further homogenized and estimated via LC-MS/MS. Different peaks for curcumin shown in LC-MS/MS study is shown here at given data sets (fig. 4).

Table 3: Antioxidant analysis of different formulations $(n=3)$

\begin{tabular}{ll}
\hline Groups & IC $_{\mathbf{5 0}}$ \\
\hline CU & $41.32 \pm 4.3$ \\
CU: GU & $28.91 \pm 3.7$ \\
CU: CAS & $25.07 \pm 2.3$ \\
CU: CAS: GU & $27.89 \pm 2.5$ \\
\hline
\end{tabular}

All data are given in mean \pm SD

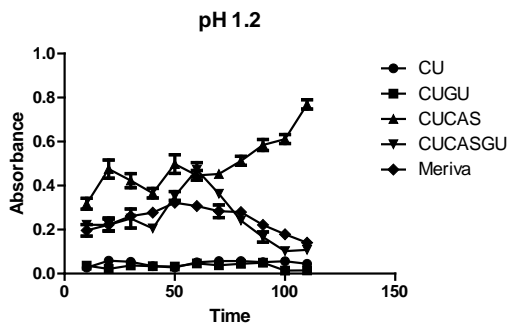

pH 1.2

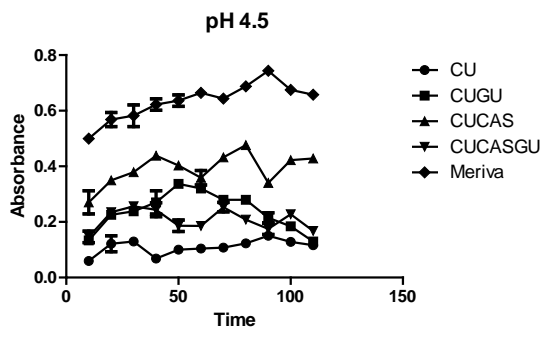

pH 4.5

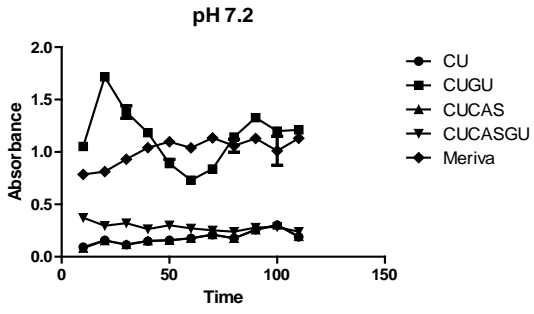

pH 7.2

Fig. 3: In vitro release profile of curcumin formulation ( $\mathrm{pH}: 1.2,4.5$ and 7.2), CU: curcumin standard, CUGU: curcumin-glutathione mixture, CUCAS: curcumin-casein, CUCASGU: curcumin-casein-glutathione, MF: marketed formulation; data represented in mean \pm SD

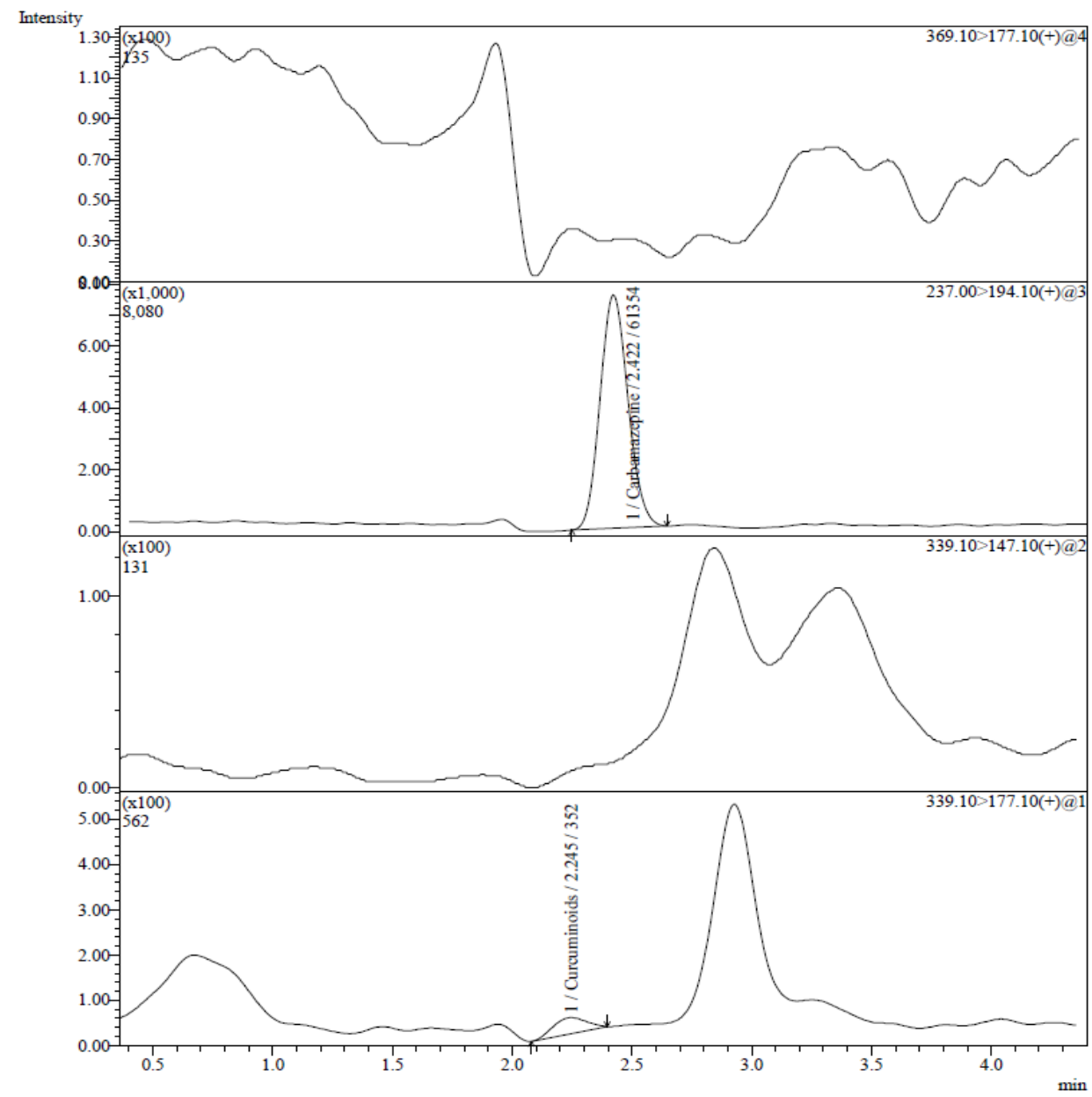

Fig. 4: Intensity of Curcumin in LC-MS/MS analysis 
The biodistribution data shows that formulation CUCASGU reaches $75 \mathrm{ng} / \mathrm{g}$ in the brain as compared to $1.22 \mathrm{ng} / \mathrm{g}$ in plain curcumin. The data shows that CUCASGU formulation removal does not occur significantly in the lung, kidney, spleen or liver as observed with other groups moreover it is focused on brain delivery only. Thus, formulation CUCASGU is renamed as CUR-CA-THIONE (fig. 5).

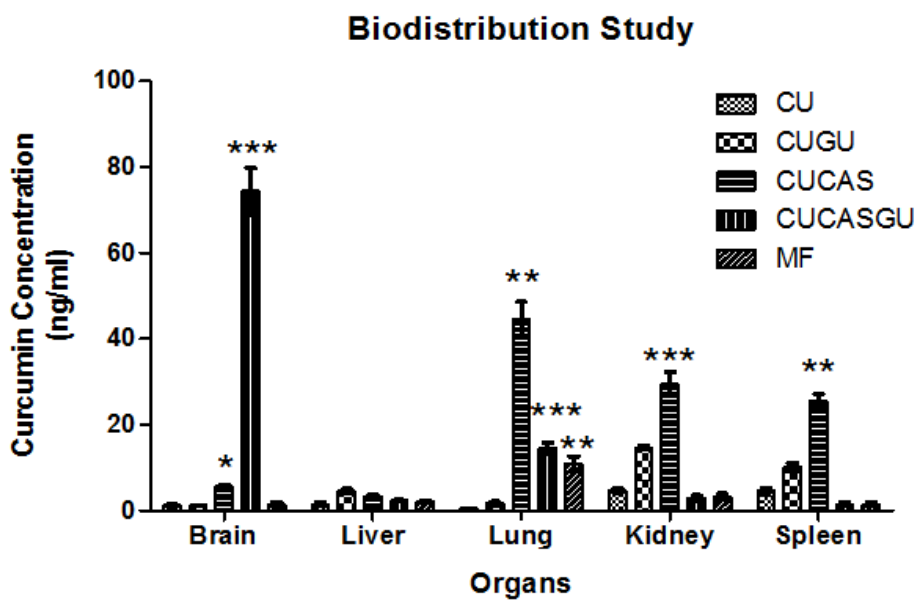

Fig. 5: Curcumin bio distribution study ( $n=6)$, CU: curcumin standard, CUGU: curcumin-glutathione mixture, CUCAS: curcumin-casein, CUCASGU: curcumin-casein-glutathione, MF: marketed formulation; all data are mentioned in mean $\pm S D$; ${ }^{\prime \prime \prime}=p<0.05,{ }^{* * *^{\prime}}=p<0.01,{ }^{\prime} * * *^{\prime}=p<0.001$

Table 4: Curcumin bio distribution study

\begin{tabular}{llllll}
\hline & CU & CUGU & CUCAS & CUCASGU \\
\hline Brain & $1.23 \pm 0.29$ & $1.19 \pm 0.15$ & $5.56 \pm 0.47$ & $74.41 \pm 5.30$ & $2.32 \pm 0.21$ \\
Liver & $1.56 \pm 0.35$ & $4.62 \pm 0.46$ & $3.36 \pm 0.24$ & $1.38 \pm 0.48$ & $2.08 \pm 0.25$ \\
Lung & $0.46 \pm 1.55$ & $1.72 \pm .41$ & $29.56 \pm 4.02$ & $14.54 \pm 1.30$ \\
Kidney & $4.70 \pm 0.39$ & $14.69 \pm 0.44$ & $25.52 \pm 1.67$ & $2.88 \pm 0.70$ \\
Spleen & $4.77 \pm 0.49$ & $10.18 \pm 0.93$ & $1.49 \pm 0.37$ & $3.25 \pm 0.67$ \\
\hline
\end{tabular}

CU: curcumin standard, CUGU: curcumin-glutathione mixture, CUCAS: curcumin-casein, CUCASGU: curcumin-casein-glutathione, MF: marketed formulation; all data are mentioned in mean \pm SD.

\section{DISCUSSION}

Curcumin has been proved to have significant anti-oxidant, antiinflammatory, neurodegenerative and many other disorders but is not prescribed therapeutically due to its low bioavailability $[34,35]$. Moreover, aqueous solubility is also an issue with curcumin leading to poor absorption via the oral route and thereby going to first-pass metabolism [36]. Thus, currently prepared a formulation of curcumin with casein and glutathione has proved to increase its water solubility to $15 \mathrm{mg} / \mathrm{ml}$ thereby increasing its absorption through the oral route. Entrapment efficiency helps in the understanding content of active moiety in a molecule while its DSC shows a change in enthalpy related temperature or physical or chemical interaction. A focus on entrapment efficiency of the drug was observed in $90 \%$ with no change in DSC analysis that ranges between $170^{\circ}-180{ }^{\circ} \mathrm{C}$ and anti-oxidant characteristic showed the $\mathrm{IC}_{50}$ value of $25-30$

The in vitro release profile provided information of release kinetics at different $\mathrm{pH}$ of 1.2, 4.5 and 7.2 as the drug is sensitive to $\mathrm{pH}$ [15]. Results showed the release of the drug between 20-60 min for most $\mathrm{pH}$ stages. Furthermore, in vivo biodistribution study helps in understanding absorption uptake of the drug by different tissue [37, 38]. A $2 \mathrm{~g} / \mathrm{kg}$ single dose was given to male wistar rats through oral gavage with same time intervals as in vitro release profile and formulated curcumin reached brain at $75 \mathrm{ng} / \mathrm{g}$ while $1.22 \mathrm{ng} / \mathrm{g}$ for plain curcumin [9].

So, CUR-CA-THIONE increased the water solubility of curcumin thereby signifying an increase in absorption through the oral route. A relative increase in bioavailability due to an increase in solubility was observed and thereby available to the brain. Thus, application of CUR-CA-THIONE in terms of brain-related disorder needs to be studied further in detail.

\section{CONCLUSION}

The present study has shown a great potential of exploration of CUR-CA-THIONE formulation further in terms of its pharmacological potential. The CUR-CA-THIONE has proved our objective and obtained a water soluble and brain bioavailable curcumin. A wonder drug curcumin has a great potential in different ailments, and with an increase of water solubility and bioavailability, it could open doors to a new avenue. This, CUR-CA-THIONE needs to be explored further for its related brain disorders.

\section{ACKNOWLEDGMENT}

I would like to thank Institute of Pharmacy, Nirma University for providing the necessary space to work.

\section{CONFLICTS OF INTERESTS}

\section{Declared none}

\section{REFERENCES}

1. Chandran B, Goel A. A randomized, pilot study to assess the efficacy and safety of curcumin in patients with active rheumatoid arthritis. Phyther Res 2012;26:1719-25.

2. Chanpoo M, Petchpiboonthai H, Panyarachun B, Anupunpisit V. Effect of curcumin in the amelioration of pancreatic islets in streptozotocin-induced diabetic mice. J Med Assoc Thai 2010;93 Suppl 6:152-9.

3. Hong D, Zeng X, Xu W, Ma J, Tong Y, Chen Y. Altered profiles of gene expression in curcumin-treated rats with experimentally induced myocardial infarction. Pharmacol Res 2010;61:142-8.

4. Ranjan AP, Mukerjee A, Helson L, Gupta R, Vishwanatha JK. Efficacy of liposomal curcumin in a human pancreatic tumor xenograft model: inhibition of tumor growth and angiogenesis. Anticancer Res 2013;33:3603-9. 
5. Quitschke W, Steinhauff N, Rooney J. The effect of cyclodextrinsolubilized curcuminoids on amyloid plaques in Alzheimer transgenic mice: brain uptake and metabolism after intravenous and subcutaneous injection. Alzheimers Res Ther 2013;5:16.

6. Holder G, Plummer J, Ryan A. The metabolism and excretion of curcumin (1,7-bis-(4-hydroxy-3-methoxyphenyl)-1,6-heptadiene3,5-dione) in the rat. Xenobiotica 1978;8:761-8.

7. Ravindranath V, Chandrasekhara N. In vitro studies on the intestinal absorption of curcumin in rats. Toxicology 1981;20:251-7.

8. Ringman J, Frautschy S, Cole G, Masterman D, Cummings J. A potential role of the curry spice curcumin in Alzheimer's disease. Curr Alzheimer's Res 2005;2:131-6.

9. Anand P, Kunnumakkara A, Newman R, Aggarwal B. Bioavailability of curcumin: problems and promises. Mol Pharm 2007;4:807-18.

10. Shelat P, Mandowara V, Gupta D, Patel S. Formulation of curcuminoid loaded solid lipid nanoparticles in order to improve oral bioavailability. Int J Pharm Pharm Sci 2015;7:7-11.

11. Ng T, Chiam P, Lee T, Chua H, Lim L, Kua E. Curry consumption and cognitive function in the elderly. Am J Epidemiol 2006;164:898-906.

12. Begum A, Jones M, Lim G, Morihara T, Kim P, Heath D, et al. Curcumin structure-function, bioavailability, and efficacy in models of neuroinflammation and Alzheimer's disease. J Pharmacol Exp Ther 2008;326:196-208.

13. Garcia-Alloza M, Borrelli LA, Rozkalne A, Hyman BT BB. Curcumin labels amyloid pathology in vivo, disrupts existing plaques, and partially restores distorted neurites in an Alzheimer, mouse model. J Neurochem 2007;102:1094-104.

14. Leung $M$, Kee $T$. Effective stabilization of curcumin by association to plasma proteins: human serum albumin and fibrinogen. Langmuir 2009;25:5773-7.

15. Wang Y, Pan M, Cheng A, Lin L, Ho Y, Hsieh C, et al. Stability of curcumin in buffer solutions and characterization of its degradation products. J Pharm Biomed Anal 1997;15:1867-76.

16. Vyas N, Patel S. Simultaneous estimation of curcuminoids, piperine, and gallic acid in an ayurvedic formulation by the validated high-performance thin layer chromatography method. Asian J Pharm Clin Res 2016;9 Suppl 2:117-22.

17. Kurmi R, Mishra D, Jain D. Solid dispersion: a novel means of solubility enhancement. J Crit Rev 2016;3:1-8.

18. Sies H. Glutathione and its role in cellular functions. Free Radical Biol Med 1999;27:916-21.

19. N Willmott, GA Magee, J Cummings G. Doxorubicin-loaded casein microspheres: protean nature of drug incorporation. J Pharm Pharmacol 1992;44:472-5.

20. Das S, Chaudhury A. Recent advances in lipid nanoparticle formulations with the solid matrix for oral drug delivery. AAPS PharmSciTech 2011;12:62-76.

21. Suzuki K, Price J. Microencapsulation and dissolution properties of a neuroleptic in a biodegradable polymer, poly(d,l-lactide). J Pharm Sci 1985;74:21-4.

22. Athira GK, Jyothi AN. Preparation and characterization of curcumin loaded cassava starch nanoparticles with improved cellular absorption. Int J Pharm Pharm Sci 2014;6:171-6.

23. Bhalekar M, Pokharkar V, Madgulkar A, Patil N, Patil N. Preparation and evaluation of miconazole nitrate-loaded solid lipid nanoparticles for topical delivery. AAPS PharmSciTech 2009;10:289-96.

24. Muddukrishna B, Dengale S, Shenoy G, Bhat K. Preparation, solid state characterisation of paclitaxel and naringen cocrystals with improved solubility. Int J Appl Pharm 2016;8:32-7.

25. Wan S, Sun Y, Qi X, Tan F. Improved bioavailability of poorly water-soluble drug curcumin in cellulose acetate solid dispersion. AAPS PharmSciTech 2012;13:159-66.

26. Jangde $R$, Singh $D$. Investigation of drug-excipients compatibility of ellagic acid for development of formulation containing lipososmes. UK J Pharm Biosci 2014;2:15-8.

27. Blois M. Antioxidant determinations by the use of a stable free radical. Nature 1958;181:1199-200.

28. Kumar A, Singh M, Singh P, Singh S, Raj P, Kapil D. Antioxidant efficacy and curcumin content of turmeric (Curcuma longa L.). Int J Curr Pharm Res 2016;8:112-4

29. Jain A, Dhawan V, Sarmento B, Nagarsenker M. In vitro and ex vivo evaluations of lipid anti-cancer nanoformulations: insights and assessment of bioavailability enhancement. AAPS PharmSciTech 2016;17:553-71.

30. Rachmawati H, Edityaningrum C, Mauludin R. Molecular inclusion complex of the curcumin- $\beta$-cyclodextrin nanoparticle to enhance curcumin skin permeability from hydrophilic matrix gel. AAPS PharmSciTech 2013;14:1303-12.

31. John F, George J. Curcumin encapsulated alginate/pluronic block copolymer micelles as a promising therapeutic agent. UK J Pharm Biosci 2014;2:6-12.

32. Berginc K, Skalko-Basnet N, Basnet P, Kristl A. Development and evaluation of an in vitro vaginal model for assessment of drug's biopharmaceutical properties: curcumin. AAPS PharmSciTech 2012;13:1045-53.

33. Teixeira C, Mendonça L, Bergamaschi M, Queiroz R, Souza G, Antunes L, et al. Microparticles containing solid curcumin dispersion: stability, bioavailability, and anti-inflammatory activity. AAPS PharmSciTech 2015;17:252-61.

34. Kakkar V, Kaur I. Evaluating potential of curcumin loaded solid lipid nanoparticles in aluminium induced behavioural, biochemical and histopathological alterations in mice brain. Food Chem Toxicol 2011;49:2906-13.

35. Agrawal R, Sandhu S, Sharma I, Kaur I. Development and evaluation of curcumin-loaded elastic vesicles as an effective topical antiinflammatory formulation. AAPS PharmSciTech 2015;16:364-74.

36. Yadav V, Suresh S, Devi K, Yadav S. Effect of cyclodextrin complexation of curcumin on its solubility and antiangiogenic and anti-inflammatory activity in rat colitis model. AAPS PharmSciTech 2009;10:752-62.

37. Zhongfa L, Chiu M, Wang J, Chen W, Yen W, Fan-Havard P, et al. Enhancement of curcumin oral absorption and pharmacokinetics of curcuminoids and curcumin metabolites in mice. Cancer Chemother Pharmacol 2012;69:679-89.

38. Yang K, Lin L, Tseng T, Wang S, Tsai T. Oral bioavailability of curcumin in rat and the herbal analysis from curcuma longa by LC-MS/MS. J Chromatogr B 2007;853:183-9.

\section{How to cite this article}

- Devang Y Shelat, Sanjeev R Acharya. Cur-CA-Thione: a novel curcumin concoction with enhanced water solubility and brain bio-availability. Int J Pharm Pharm Sci 2016;8(12):265-270. 